\title{
Sensitive detection of estriol hormone in creek water using a sensor platform based on carbon black and silver nanoparticles
}

\author{
Paulo A. Raymundo-Pereira ${ }^{\mathrm{a}, \mathrm{b}, *}$, Anderson M. Campos ${ }^{\mathrm{b}}$, Fernando C. Vicentini ${ }^{\mathrm{c}, * *}$, Bruno \\ C. Janegitz ${ }^{\mathrm{d}}$, Camila D. Mendonça ${ }^{\mathrm{b}}$, Leonardo N. Furinie ${ }^{\mathrm{e}}$, Naiza V. Boas ${ }^{\mathrm{b}}$, Marcelo L. Calegaro ${ }^{\mathrm{b}}$, \\ Carlos J.L. Constantino ${ }^{\mathrm{e}}$, Sergio A.S. Machado ${ }^{\mathrm{b}}$, Osvaldo N. Oliveira Jr., a \\ a São Carlos Institute of Physics, University of São Paulo, São Carlos, São Paulo CEP 13566-590, Brazil \\ b Institute of Chemistry of São Carlos, University of São Paulo, São Carlos, São Paulo CEP 13566-590, Brazil \\ c Center of Natural Sciences, Federal University of São Carlos, 18290-000 Buri, SP, Brazil \\ d Department of Natural Sciences, Mathematics and Education, Federal University of São Carlos, 13600-970 Araras, SP, Brazil \\ ' School of Technology and Applied Sciences, UNESP Univ Estadual Paulista, 19060-900 Presidente Prudente, SP, Brazil
}

\section{A R T I C L E I N F O}

\section{Keywords:}

Sensor platform

Silver nanoparticles

Carbon black

Sensing

Estriol

Endocrine disruptor

\begin{abstract}
A B S T R A C T
We report the electrochemical detection of estriol using carbon black nanoballs (CNB) decorated with silver nanoparticles (AgNP) as electrode material. Homogeneous, porous films on glassy carbon electrodes (GCE) were obtained, with diameters of $20-25 \mathrm{~nm}$ for $\mathrm{CNB}$ and $5-6 \mathrm{~nm}$ for AgNP. CNB/AgNP electrodes had increased conductivity and electroactive area in comparison with bare GCE and GCE/CNB, according to cyclic voltammetry and electrochemical impedance spectroscopy. The oxidation potential peak was also down shifted by $93 \mathrm{mV}$, compared to the bare GC electrode. Differential pulse voltammetry data were obtained in $0.1 \mathrm{~mol} \mathrm{\textrm {L } ^ { - 1 }}$ PBS ( $\mathrm{pH} 7.0$ ) to detect estriol without the purification step, in the linear range between 0.2 and $3.0 \mu \mathrm{mol} \mathrm{L}{ }^{-1}$ with detection and quantification limits of 0.16 and $0.5 \mu \mathrm{mol} \mathrm{L} \mathrm{L}^{-1}\left(0.04\right.$ and $\left.0.16 \mathrm{mg} \mathrm{L}^{-1}\right)$, respectively. The sensor was used to detect estriol in a creek water sample with the same performance as in the official methodology based on high performance liquid chromatography.
\end{abstract}

\section{Introduction}

Carbon-based nanostructures such as fullerenes, nanotubes and graphene are among the most investigated materials ever, being utilized in several applications. Their use in sensors and biosensors, in particular, is often motivated by their increased electron transfer rate and decreased overpotential in electrochemical processes [1-3]. An intrinsic disadvantage though lies in the high cost of their synthesis and some difficulty for immobilization on electrode surfaces. These limitations may explain why these carbon nanostructures have not reached sensing applications in real scenarios, with mass production. A possible avenue to overcome such limitations is to use "less noble" carbon materials, e.g. carbon black powder which is now mostly employed as reinforcing filler in rubber production [4]. The most environmentally recomended industrial method to produce carbon black is thermal plasma pyrolysis of organic materials which can generate nanospheres that have been applied in lithium ion batteries, supercapacitor electrodes, fuel cells and in electrocatalysis [5]. In electroanalytical sensing applications, carbon black nanospheres have been applied in the electrochemical detection of environmental, biological and foodstuff analytes [3].

In this study, we combined carbon nanoballs (CNB) with silver nanoparticles to obtain electrochemical sensors capable of detecting the estrogenic hormone estriol ((16a,17ß)-estra-1,3,5(10)-triene$3,16,17$-triol). Estriol is used to prevent and in treating disorders caused by hormone deficiency, heart disorder, cancer, hyperandrogenism, osteoporosis and urogenital diseases in women [6]. It is also classified as an endocrine disruptor that poses health risks to humans and wildlife because it is removed in the urine and is not degraded during sewage treatment [6,7]. Detection of trace amounts of estriol is therefore relevant in monitoring the environment, and this has been made with techniques such as gas chromatography, high performance liquid chromatography (HPLC) with a variety of detectors [8,9], spectrophotometry [10], chemiluminescence [11], immunoassays $[12,13]$, immunosorbent assay (ELISA) [14] and capillary electrophoresis $[15,16]$. These analytical procedures, however, require time-

\footnotetext{
* Corresponding author at: São Carlos Institute of Physics, University of São Paulo, São Carlos, São Paulo CEP 13566-590, Brazil.

** Corresponding author.

E-mail addresses: pauloaugustoraymundopereira@gmail.com (P.A. Raymundo-Pereira), fercv02@yahoo.com.br (F.C. Vicentini).
} 
consuming pre-treatment of samples prior to the analysis, including extraction and clean-up procedures. Only after this pre-treatment are the samples compatible with chromatographic detection, which also generates waste containing organic solvents and makes the detection more expensive, complicated and unsuitable for routine analysis [6].

With electrochemical sensors, as is done here, we can achieve a fast determination and quantification since estriol is electroactive and can be electrochemically oxidized $[6,17]$. Indeed, estriol has been detected in other highly selective transducers, such as boron-doped diamond electrode, graphene, carbon nanotubes, platinum and antimony nanoparticles $[6,7,17-20]$. As it will be shown in this article, by exploiting the synergy between CNB and silver nanoparticles we have been able to detect estriol with high sensitivity, no effect from important interferents and in natural surface waters. The synergistic combination between these two nanomaterials with large surface areas provides improved electrocatalytic activity and leads to excellent features for estriol sensing. The use of metallic nanostructures such as silver nanoparticles also decreases adsorption of electroxidation products of estriol on the sensor platform.

\section{Experimental section}

\subsection{Chemicals and solutions}

All chemicals were of analytical grade with high purity. Silver nitrate (99\% purity) was purchased from Merck (Darmstadt, Germany). Estriol and dimethylformamide (DMF) were acquired from Sigma-Aldrich (St. Louis, MO, USA) and ethylene glycol was acquired from Carlo Erba (France). Acetonitrile, potassium hexacyanoferrate(III) $\left(\mathrm{K}_{3}\left[\mathrm{Fe}(\mathrm{CN})_{6}\right]\right)$ and potassium hexacyanoferrate(II) $\left(\mathrm{K}_{4}\left[\mathrm{Fe}(\mathrm{CN})_{6}\right]\right)$ were acquired from $\mathrm{J}$. T. Baker (Center Valley, PA, USA). VXC72R CNB was kindly donated by Cabot Corporation. The phosphate buffer solution ( $\mathrm{pH}$ 7.0) was prepared with appropriated amounts of sodium phosphate monobasic monohydrate and sodium phosphate dibasic for $0.1 \mathrm{~mol} \mathrm{~L}^{-1}$ concentration (Sigma-Aldrich (St. Louis, MO, USA)) and then used as electrolytic solution.

\subsection{Synthesis of AgNPs reduced directly on carbon nanoballs}

The silver nanoparticles were reduced directly on CNB as reported by Skrabalak et al. [21] using the polyol method with ethylene glycol (EG) as reducing agent (see Fig. 1). In the synthesis, $3.0 \mathrm{~g}$ of CNB were dispersed in $25 \times 10^{-3} \mathrm{~L}$ of $\mathrm{EG}$, to which $0.71 \mathrm{mmol}$ of $\mathrm{AgNO}_{3}$ was included with the mixture being maintained at $150{ }^{\circ} \mathrm{C}$ for $60 \mathrm{~min}$. The hybrid material was filtered in cellulose membrane and plentifully washed with ultrapure water. The product obtained was dried for $12 \mathrm{~h}$ at $90^{\circ} \mathrm{C}$ and retained in a desiccator. The hybrid material was designated as CNB-AgNP.

\subsection{Instruments}

An FEI TECNAI G2 F20 transmission electron microscope operating at $200 \mathrm{kV}$ was used for the morphological analysis of CNB-AgNP, which were ultrasonicated for $2 \mathrm{~h}$ using DMF, and the suspension was dropped on carbon-coated copper grids. X-ray powder diffraction (XRD) was performed using a Rigaku Rotaflex diffractometer model $\mathrm{RU} 200 \mathrm{~B}$ at $50 \mathrm{kV}$ and $100 \mathrm{~mA}$, with $\mathrm{Cu}_{\mathrm{Ka}}$ radiation, $\lambda=1.542 \AA$. The Raman spectra were taken with a micro-Raman in-Via Renishaw spectrograph (Renishaw Ltd, Gloucestershire, UK) coupled to a Leica optical microscope, under excitation at $514.5 \mathrm{~nm}$, diffraction grating of $1800 \mathrm{~L} \mathrm{~mm}^{-1}$, acquisition time of $10 \mathrm{~s}$ and 10 accumulations.

A potentiostat model PGSTAT 302 Autolab electrochemical (Eco Chemie, Utrecht, Netherlands) controlled by NOVA software was used in the electrochemical experiments with a conventional three-electrode system (electrochemical cell). This cell contained a GC electrode coated with a CNB-AgNP film as a working electrode (referred to as
CNB-AgNP/GCE), an $\mathrm{Ag} / \mathrm{AgCl}$ electrode in $\mathrm{KCl}\left(3.0 \mathrm{~mol} \mathrm{~L}^{-1}\right)$ as reference electrode, and a platinum wire as auxiliary electrode. CV measurements were conducted in a potential range between -0.2 and $+0.6 \mathrm{~V}$ in a scan rate of $50 \mathrm{mV} \mathrm{s}^{-1}$. Differential pulse voltammetry (DPV) experiments were carried out in a potential range between -0.2 and $+0.6 \mathrm{~V}$ at a scan rate of $5 \mathrm{mV} \mathrm{s}^{-1}$, pulse amplitude $50 \mathrm{mV}$ and modulation time at $1 \mathrm{~ms}$ for all electrochemical and electroanalytical studies. The electrochemical impedance spectroscopy (EIS) data were collected using FRA2 software in a frequency range from $0.1 \mathrm{~Hz}$ to $100 \mathrm{kHz}$ at an amplitude of $10 \mathrm{mV}$ and under open circuit potential (OCP) conditions with $0.1 \mathrm{~mol} \mathrm{~L}^{-1} \mathrm{KCl}$ solution containing $5.0 \times$ $10^{-3} \mathrm{~mol} \mathrm{~L}^{-1}$ of $\mathrm{K}_{3}\left[\mathrm{Fe}(\mathrm{CN})_{6}\right] / \mathrm{K}_{4}\left[\mathrm{Fe}(\mathrm{CN})_{6}\right]$.

The chromatographic measurements were made using a Shimadzu HPLC system with manual injector, degasser, two pumps (series LC-10 CE VP) and diode array detector (DAD), equipped with a reverse phase C18 column $(250 \times 4.6 \mathrm{~mm}$ ID, $5 \mu \mathrm{m}$ particle size $)$ C18 pre-column ( $2 \mathrm{~cm} \times 4 \mathrm{~mm}$ ID, $5 \mu \mathrm{m}$ particle), both from Ascentis ${ }^{\circ}$ Supelco.

\subsection{Preparation of the sensor platform}

The GCE surface was mechanically cleaned using silicon carbide (4000 mesh) and washed thoroughly with ultrapure water and dried in $\mathrm{N}_{2}$. Then, $1.0 \mathrm{mg}$ of CNB-AgNP was dispersed using DMF $(1.0 \mathrm{~mL})$ with ultrasonic stirring during $2 \mathrm{~h}$. A thin film coating layer $(6.0 \mu \mathrm{L})$ was dropped on the GCE surface and maintained at room temperature until the solvent evaporated.

\subsection{Analytical procedure}

The surface concentration of electroactive species was estimated using the silver oxidation peak (charge) of the CNB-AgNP/GCE surface. Then, GCE, CNB-GCE and CNB-AgNP/GCE surfaces were used with DPV under optimized parameters (pulse amplitude, scan rate and modulation time) to detect estriol, whose molecular structure is given in Fig. 1. The limit of detection was estimated using the statistical method where LOD $=a+3 S_{y / x}$, with $a$ and $S_{y / x}$ being the intercept and the standard deviation of $y$-residuals of least-squares line (linear regression), respectively. The limit of quantification (or limit of determination) was calculated using $\mathrm{LOQ}=a+10 S_{y / x}$ [22-24]. The sensitivity was calculated from the slope of the least-squares line (linear regression), $b=\sum\left[\left(x_{i}-x\right)\left(y_{i}-\bar{y}\right)\right] / \sum\left(x_{i}-x\right)^{2}[3,22-24]$. The precision of the proposed sensor platform was verified from intra-day $(\mathrm{n}=10)$ and inter-day $(\mathrm{n}=5)$ repeatability studies.

The natural surface water sample collected from a stream of São Carlos city, São Paulo, Brazil (Coordinates: $22^{\circ} 00.725^{\prime} S 47^{\circ} 54.428^{\prime}$ $\mathrm{W}$ ), required a treatment for the chromatographic assays. The sample was cleaned by filtration through a filter paper, followed by filter membrane (RC) of $0.45 \mu \mathrm{m}$ porosity and injection into the chromatographic system. The parameters utilized for estriol analysis were: injection volume of $20 \mu \mathrm{L}$; mobile phase comprising acetonitrile (A) and water (B) in isocratic mode (54\% A), running of $10 \mathrm{~min}$ at a flow rate of $1.0 \mathrm{~mL} \mathrm{~min}^{-1}$ and $\mathrm{UV}$ monitoring at $\lambda=280 \mathrm{~nm}[25,26]$. All experiments were made at room temperature, $\sim 25^{\circ} \mathrm{C}$.

The detection of estriol via electrochemical measurements - for comparison with the standard chromatographic method - was verified with the creek water spiked with varied amounts of these analytes because water samples used directly from the creek did not show any characteristic signal. Estriol detection in the natural surface water sample with the proposed method carried out in triplicate. The content of estriol in these samples was quantified and compared with the standard chromatographic method $[25,26]$ using a statistical method $[24,27]$. 


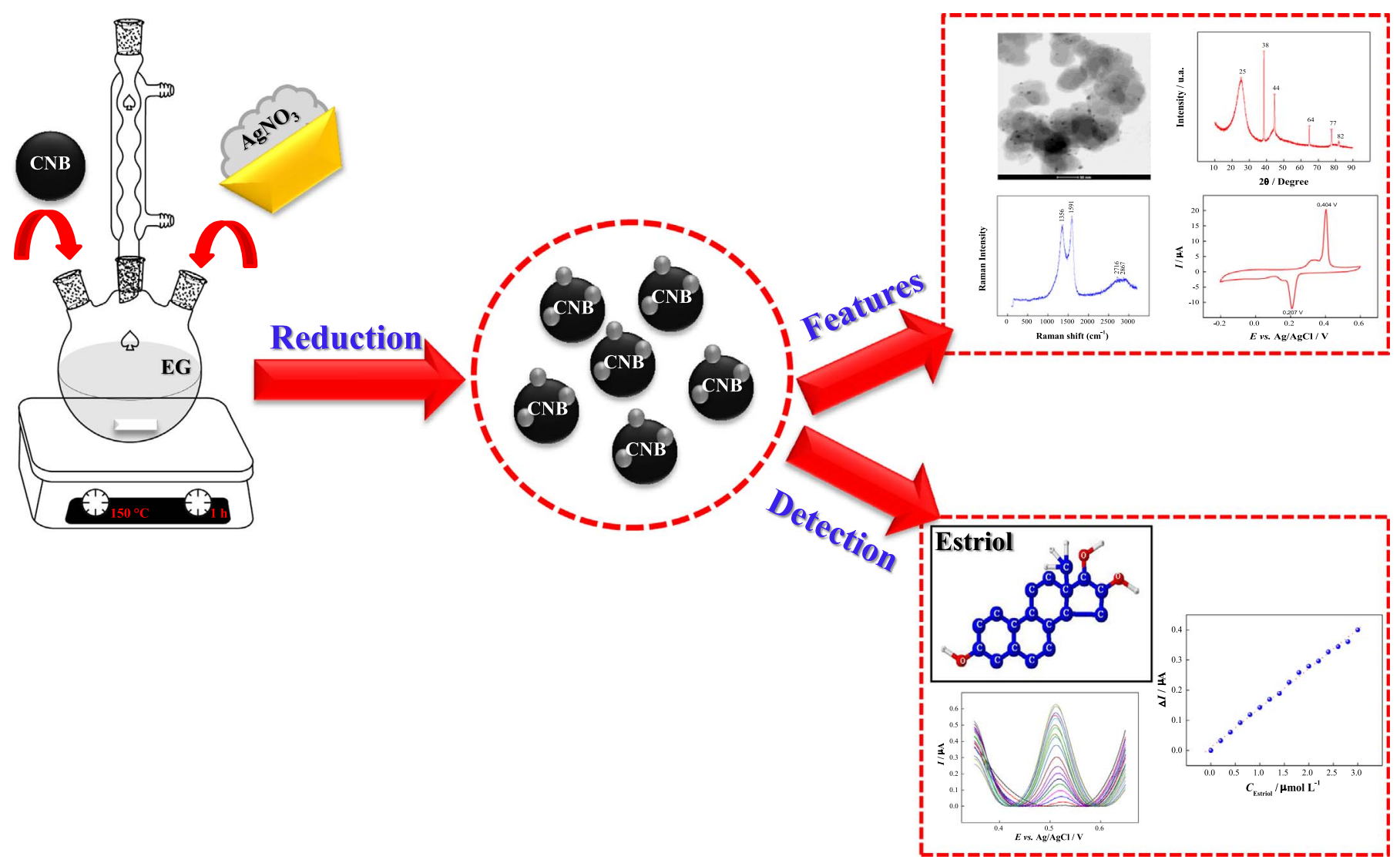

Fig. 1. Schematic diagram of different steps for preparing the sensor platform to detect estriol.

\section{Results and discussion}

\subsection{Morphological, structural and electroanalytical performance of CNB-AgNP}

A typical cyclic voltammogram for a CNB-AgNP/GCE surface in Fig. 2(A) reveals an anodic peak at $+404 \mathrm{mV}\left(E_{P A}\right)$ and a cathodic peak at $+178 \mathrm{mV}\left(E_{P C}\right)$, which are attributed to the redox process of $\mathrm{Ag}^{\mathrm{o} /+}$ in CNB-AgNP. AgNPs are oxidized to $\mathrm{Ag}^{+}$at $+400 \mathrm{mV}$ vs. $\mathrm{Ag} / \mathrm{AgCl}$ on the anodic scan, and converted of $\mathrm{Ag}^{+}$back to $\mathrm{Ag}^{0}$ at $+207 \mathrm{mV}$ vs. $\mathrm{Ag} / \mathrm{AgCl}$ on the reverse cathodic scan. The silver signal at $400 \mathrm{mV}$ was maintained for $50 \mathrm{CV}$ measurements, i.e. the AgNPs are stable and are not leached out into the solution. The amount of electroactive species on the surface $\left(\Gamma / \mathrm{mol} \mathrm{cm} \mathrm{cm}^{-2}\right)$ was estimated with $\Gamma=Q / n F A$ $[23,24]$, where $Q(\mathrm{C})$ is the background-corrected electric charge, estimated by integrating the anodic peak (in the CV at $v=5 \mathrm{mV} \mathrm{s}^{-1}$ ) in the phosphate buffer solution; $n$ is the number of electrons; $F$ is the Faraday constant $\left(96,485.34 \mathrm{C} \mathrm{mol}^{-1}\right)$; and $A$ is the surface geometric area. $Q$ was $6.04 \times 10^{-6} \mathrm{C}$, and the estimated surface concentration of $\mathrm{Ag} / \mathrm{Ag}^{+}$was $8.8 \times 10^{-10} \mathrm{~mol} \mathrm{~cm}{ }^{-2}$.

Therefore, AgNPs were successfully decorated the CNB surface, as expected from the HR-TEM micrographs in Fig. 2(B) and (C). The images of CNB-AgNP on copper grids show multiple nanoball-shapped particles decorated with AgNPs, with size distribution of ca. 20$25 \mathrm{~nm}$ (for CNB) and 5-6 nm (for AgNPs). The AgNPs were welldistributed throughout $\mathrm{CNB}$ and no agglomerate was observed, with the carbon nanoballs maintaining their shape after decoration with AgNPs. Significantly, the EDX spectrum in Fig. 2(D) shows only carbon, silver and oxygen, in addition to copper signals from HRTEM grids, thus indicating the absence of contaminants. The corresponding electron diffraction (SAED) pattern (inset in Fig. 2(D)) points to AgNPs with a single crystalline structure, consistent with the powder XRD pattern in Fig. 2(E). Six sharp, well defined peaks were observed at $2 \theta=38.48^{\circ}, 44.34^{\circ}, 64.65^{\circ}$ and $77.67^{\circ}$, assigned to (111), (200), (220) and (311) of the face centered cubic (fcc) structure of metallic silver, respectively (JCPDS 04-0783 [24,28]), and at $2 \theta=25.01^{\circ}$ and $44^{\circ}$ assigned to (002) and (100) planes of the hexagonal phase of the carbon support (JCPDF 73-2096 [24,29]). The well-defined strong peaks in the XRD indicate that AgNPs are crystalline, with nanometer dimensions, in agreement with the HR-TEM images.

The features observed with XRD and HR-TEM are consistent with the functionalization degree inferred from Raman spectroscopy (i.e. low surface disorder), suggesting that the hybrid nanomaterial did not induce extra defects and/or structural disorder in CNB-AgNP [24]. The Raman spectra in Fig. 2(F) exhibit two prominent graphite-related bands, assigned to the well-known $\mathrm{D}\left(\sim 1354 \mathrm{~cm}^{-1}\right)$ and $\mathrm{G}$ $\left(\sim 1596 \mathrm{~cm}^{-1}\right)$ bands, caused by defects in $\mathrm{sp}^{2}$ hybridized carbon lattices and $\mathrm{C}-\mathrm{C}$ bond stretching, respectively. No difference in position was noted for the D and G bands of CNB and CNB-AgNP samples. The broad band around $\sim 2700 \mathrm{~cm}^{-1}$ consists of two smaller bands, namely 2D $\left(\sim 2670 \mathrm{~cm}^{-1}\right)$ and $\mathrm{D}+\mathrm{D}^{\prime}\left(\sim 2832 \mathrm{~cm}^{-1}\right)$ [24,30]. The ratio of integrated areas of the $\mathrm{D}^{-}$and $\mathrm{G}$-bands $\left(\mathrm{I}_{\mathrm{D}} / \mathrm{I}_{\mathrm{G}}\right)$ - in agreement with Ferrari and Robertson [31] - for CNB and CNB-AgNP was 1.01 and 0.99 , respectively, as expected from the functionalization degree (i.e. surface disorder) [32]. The ratio of 0.99 for CNB-AgNP is comparable to its precursor (1.01), confirming that there are no extra defects defects in CNB-AgNP [33,34], as observed with the XRD data.

The synergy between AgNP and CNB was exploited for detection of estriol in Fig. 3A where a considerably higher oxidation current was observed for CNB-AgNP/GCE in the presence of $7.0 \mu \mathrm{mol} \mathrm{L}^{-1}$ estriol. This higher current is due to the increased surface conductivity that facilitates charge transfer between the analyte and the sensor platform, in addition to the electrocatalytic activity promoted by nanomaterials with large surface areas [24]. Taking the current intensity of the peak from voltammograms for several estriol concentrations (see Figs. S1), one obtains linear plots in Fig. 3B for CNB-AgNP/GCE with high 

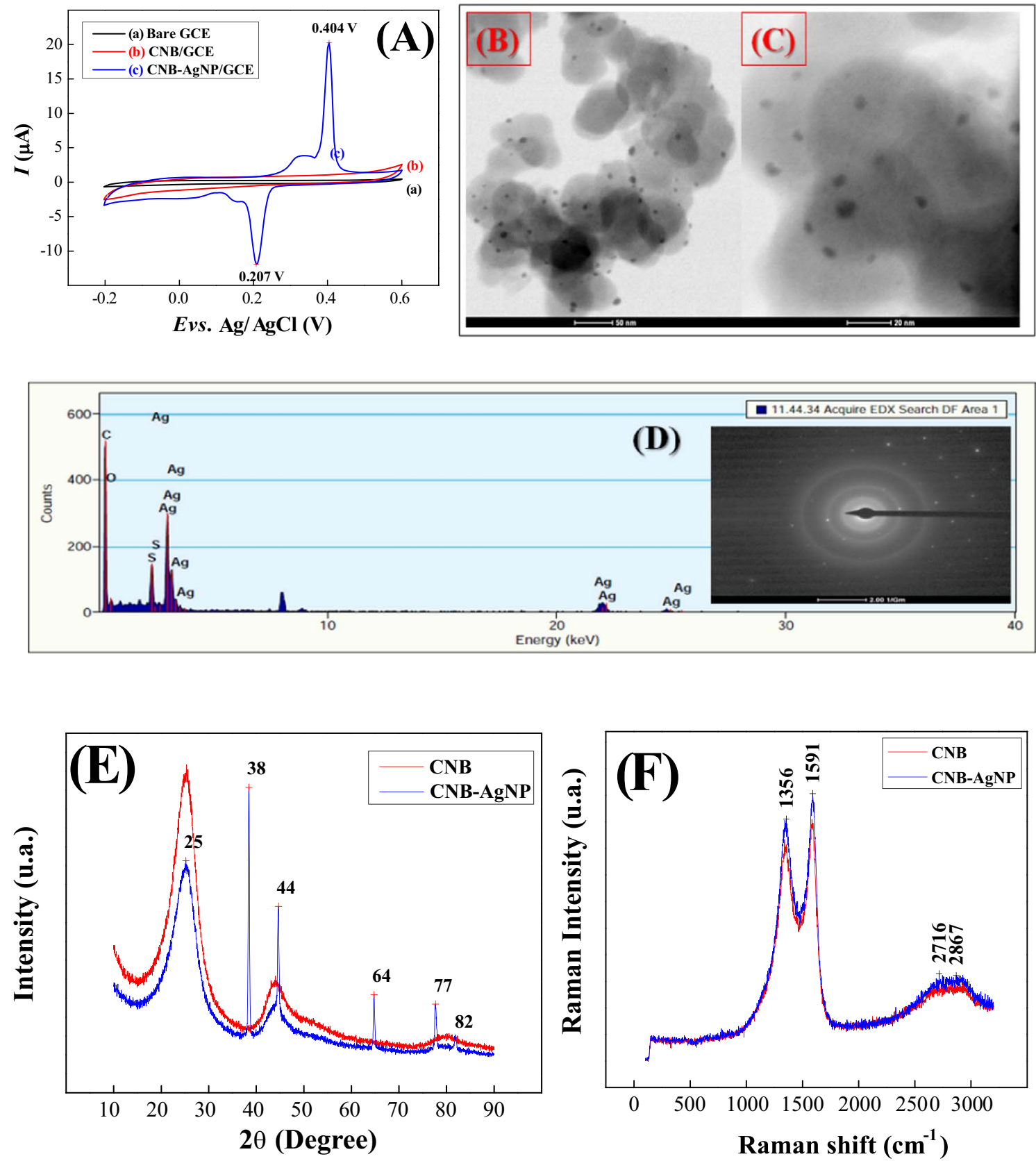

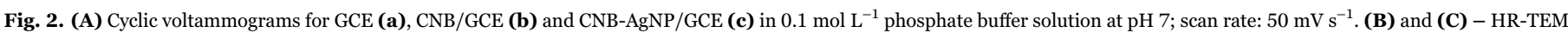

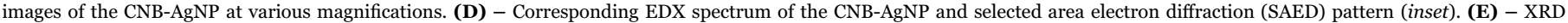
patterns of CNB and CNB-AgNP hybrid nanomaterial, respectively. (F) - Raman spectra of CNB and CNB-AgNP hybrid nanomaterial, respectively.

sensitivity $\left(7.9 \times 10^{-2} \mathrm{~A} \mathrm{~mol} \mathrm{~L}{ }^{-1}\right)$. In contrast, the plots for bare GCE $\left(4.7 \times 10^{-3} \mathrm{~A} \mathrm{~mol} \mathrm{~L}^{-1}\right)$ and $\mathrm{CNB} / \mathrm{GCE}\left(1.7 \times 10^{-2} \mathrm{~A} \mathrm{~mol} \mathrm{~L}^{-1}\right)$ show a lower sensitivity and were not as linear in the range analyzed due to the inefficiency in the electrooxidation of estriol. The linear regression for the electroanalytical response using GCE, CNB/GCE and CNB-AgNP/ GCE gave:

GCE: $I_{\mathrm{P}}(\mathrm{A})=3.8 \times 10^{-9}+4.7 \times 10^{-3} C_{\text {estriol }}\left(\mathrm{mol} \mathrm{L}^{-1}\right), r=0.994, n$ $=6$.

CNB/GCE: $I_{\mathrm{P}}(\mathrm{A})=1.5 \times 10^{-9}+1.7 \times 10^{-2} C_{\text {estriol }}\left(\mathrm{mol} \mathrm{L}^{-1}\right), r=$ $0.997, n=11$.

CNB-AgNP/GCE: $I_{\mathrm{P}}(\mathrm{A})=9.1 \times 10^{-8}+7.9 \times 10^{-2} C_{\text {estriol }}\left(\mathrm{mol} \mathrm{L}^{-1}\right)$, $r=0.992, n=16$.

The only platform that showed a linear relationship between $I_{\mathrm{pa}}$ and estriol concentration from $0.2 \times 10^{-6}$ to $3.0 \times 10^{-6} \mathrm{~mol} \mathrm{~L}^{-1}$ was CNBAgNP/GCE due to the synergy between CNB and AgNP as depicted in
Fig. 3(C). The linear regression gives $\Delta I_{\mathrm{P}}(\mathrm{A})=(1.0 \pm 0.3) \times 10^{-8}+$ $(0.13 \pm 0.002) C_{\text {estriol }}\left(\mathrm{mol} \mathrm{L}^{-1}\right), r=0.999, n=16$. The LOD and LOQ were $1.6 \times 10^{-7}$ and $5.5 \times 10^{-7} \mathrm{~mol} \mathrm{~L}^{-1}$, respectively. The insets in Fig. $3 \mathrm{~B}$ and $\mathrm{C}$ show a satisfactory distribution of residuals in the regression diagnostics based on residual plots. Indeed, the residuals are $50 \%$ above and $50 \%$ below zero, consistent with a correct calibration model, with the exception of $y_{10}$ which might be an outlier.

The electron exchange can be influenced by surface chemistry and the nanomaterial $[24,35,36]$, and EIS can provide additional insights into electron transfer of carbon nanoballs. Fig. 3(D) shows that CNB has the highest $R_{\mathrm{ct}}(770.97 \Omega$ ) due to the abundant presence of oxygen groups [35]. The number of oxygen-containing groups decreases with silver reduction on the CNB surface, which explains why CNB-AgNP/ GCE has the lowest $R_{c t}$, i.e., $125.82 \Omega$, while for the bare GCE $R_{c t}$ was $270.62 \Omega$. The lowest $R_{c t}$ value for CNB-AgNP/GCE is also due to the 

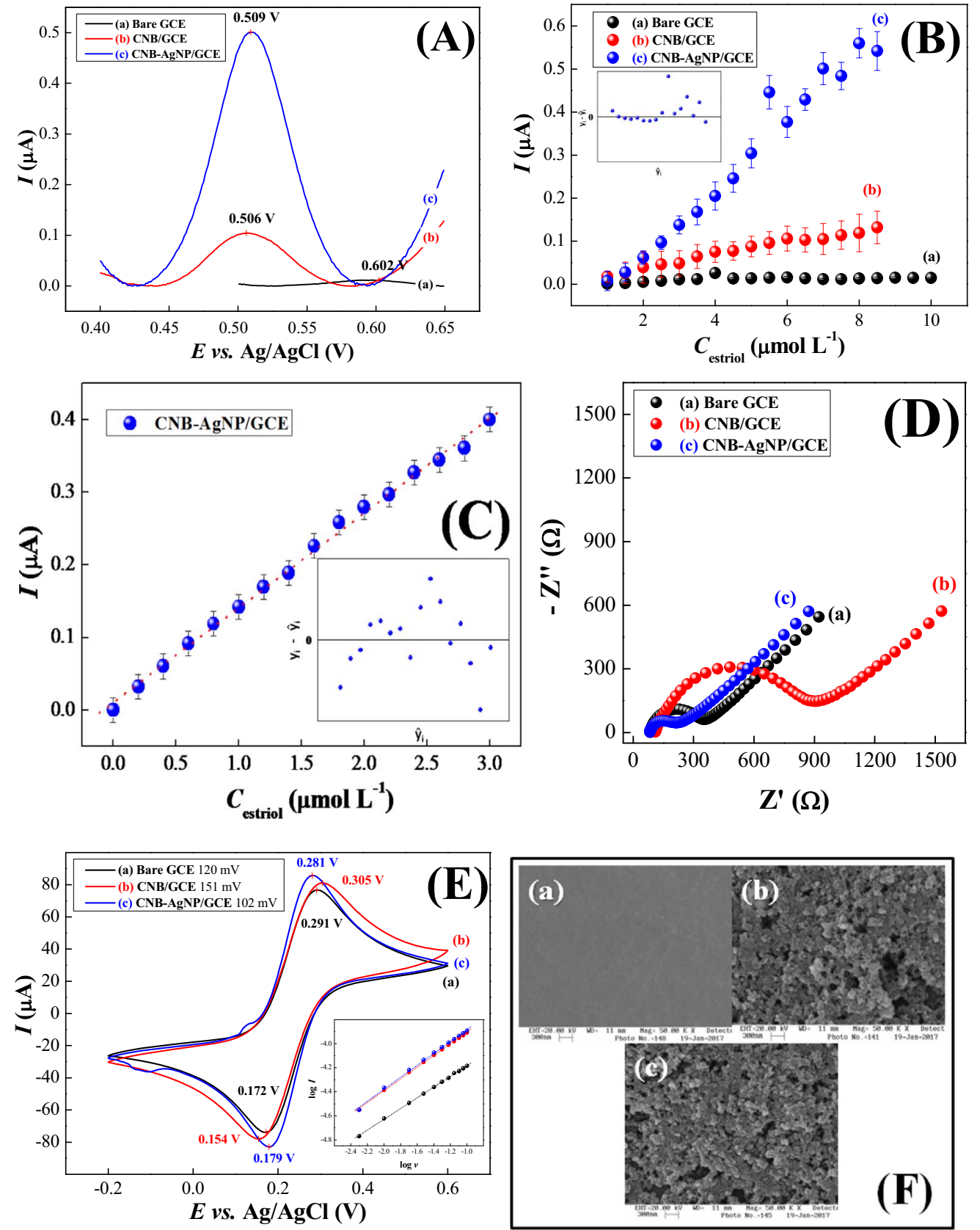

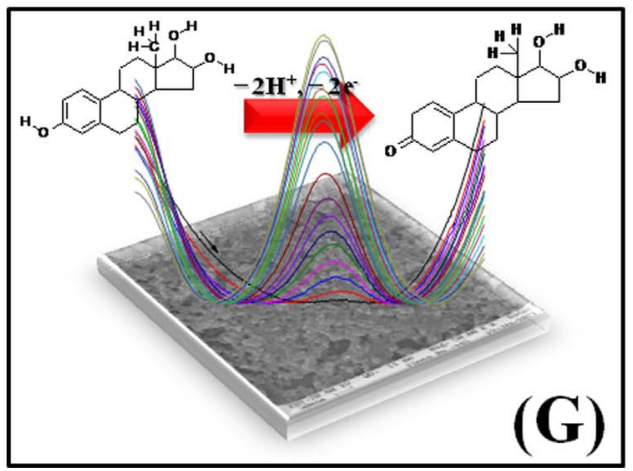




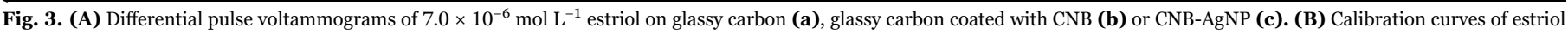

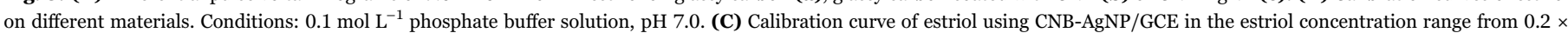

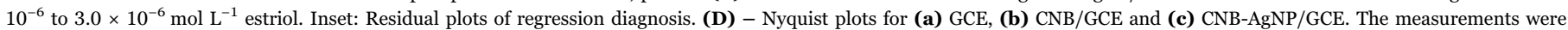

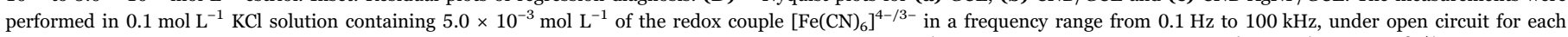

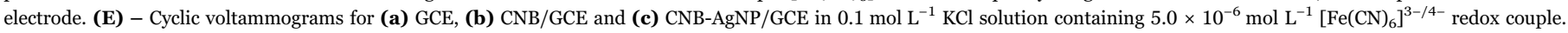

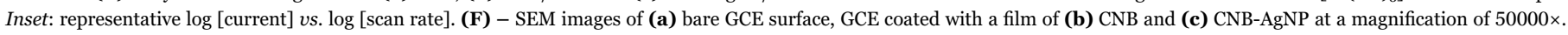
(G) - Schematic representation of electrooxidation of estriol on the CNB-AgNP/GCE sensor platform.

higher conductivity imparted by AgNPs [24,36]. The behavior inferred from the EIS analysis for CNB/GCE is the same as from the voltammetric results.

The analysis of the voltammetric profiles points to a well-defined pair of redox peaks as depicted in Fig. 3(E), with a peak-to-peak separation $\left(\Delta E_{\mathrm{P}}\right)$ of ca. 120,151 and $102 \mathrm{mV}$ (vs. $\mathrm{Ag} / \mathrm{AgCl}$ ) for the bare GCE, CNB/GCE and CNB-AgNP/GCE, respectively. Moreover, the current at the peak for CNB-AgNP/GCE was higher than for bare GCE and $\mathrm{CNB} / \mathrm{GCE}$, owing to the higher conductivity and electroactive surface of CNB-AgNP [24,35]. The increased electroactive surface arises from coating the bare GCE with a porous, ultrathin film, as indicated in Fig. 3(F). Fig. S2 shows voltammograms at scan rates ranging between 5 and $100 \mathrm{mV} \mathrm{s}^{-1}$ from which one infers that the electrochemical reaction is diffusion controlled for GCE, CNB/GCE and CNB-AgNP/GCE, as the peak current $\left(I_{\mathrm{P}}\right)$ (anodic) varied with the square root of the scan rate [37]. The slope in $\log I_{\mathrm{P}}$ versus $\log v$ plots was 0.44 (GCE bare), 0.48 (CNB/GCE) and 0.49 (CNB-AgNP/GCE), as shown in the inset in Fig. 3(E). The larger slope for CNB-AgNP/GCE surface is indicative of faster electrochemical kinetics and electrocatalytic activity promoted by nanomaterials with large surface areas [38].

The mechanism of electrochemical oxidation consists of an initial oxidation of estriol producing a phenoxy radical, followed by oxidation to a phenoxonium ion, and chemical coupling to form a ketone. This kind of mechanism can be associated to a sequence of reactions involving electron transfer-chemical process-electron transfer-chemical processes (ECEC mechanism) with the transfer of two electrons [38] as illustrated in Fig. 3(G). Ngundi and co-workers showed by GC/ MS analysis that the oxidation products correspond to a ketone derivative [39]. Here, we highlight that oxidation of estriol did not result in a polymerization reaction, which could polymerize a film and/ or bring a non-electroactive deposit [19].

The molecules that can interfere in the estriol detection in natural surface waters were also investigated. Firstly, DPV experiments were performed following estriol electrooxidation (at a fixed concentration of $5.0 \times 10^{-6} \mathrm{~mol} \mathrm{~L}^{-1}$ ). Subsequently, $5.0 \times 10^{-6} \mathrm{~mol} \mathrm{~L}^{-1}$ of sulfite, nitrite, glucose, amoxicillin, ascorbic acid, levofloxacin, sulfamethazole, acetaminophen, bisphenol A and 17- $\beta$-estradiol were individually added, and the corresponding DPV responses were recorded (Fig. S3). No additional peaks were detected for the interfering compounds within the potential window studied, suggesting that these substances do not interfere with the estriol detection. Fig. S3 gives the relative current percentages for estriol after each addition of interfering species. Levofloxacin, sulfamethaxazole, acetaminophen, bisphenol-A and 17$\beta$-estradiol indeed caused a change in the estriol oxidation current. However, because the estriol signal is maintained, it suffices to determine the percentage of change induced by each interferent to use the sensor. Therefore, CNB-AgNP/GCE was able to detect estriol in the presence of these interferences and can be applied in quantification of real samples.

Repeatability of the sensor platform was evaluated using $2.6 \times$ $10^{-6} \mathrm{~mol} \mathrm{~L}^{-1}$ of estriol containing $0.1 \mathrm{~mol} \mathrm{~L}^{-1}$ phosphate buffer solution ( $\mathrm{pH} 7.0$ ), and the relative standard deviation (RSD) was $7.1 \%$ for anodic peak current for inter-day repeatability $(n=10)$. The stability was also evaluated with the electrochemical response decreasing by only $5.5 \%$ (RSD) after $50 \mathrm{DPV}$ profiles. This could be attributed to the chemical stability of CNB-AgNP and the surface film obtained with DMF. When five co-fabricated sensors were utilized, RSD for inter-day repeatability was $2.4 \%$, indicating the reproducibility of the sensor platform fabrication procedure.

3.2. Chromatographic quantification of the endocrine disruptor in natural waters and statistical comparison with the voltammetric results

Table 1 contains the results for nine creek water samples using the proposed method and the same samples were compared with the standard method using HPLC. In order to test the robustness of CNBAgNP/GCE for a estriol sensing application, the electroxidation of estriol was performed by different operators (among the authors) in different laboratories and equipment. Fig. S4A depicts the analytical

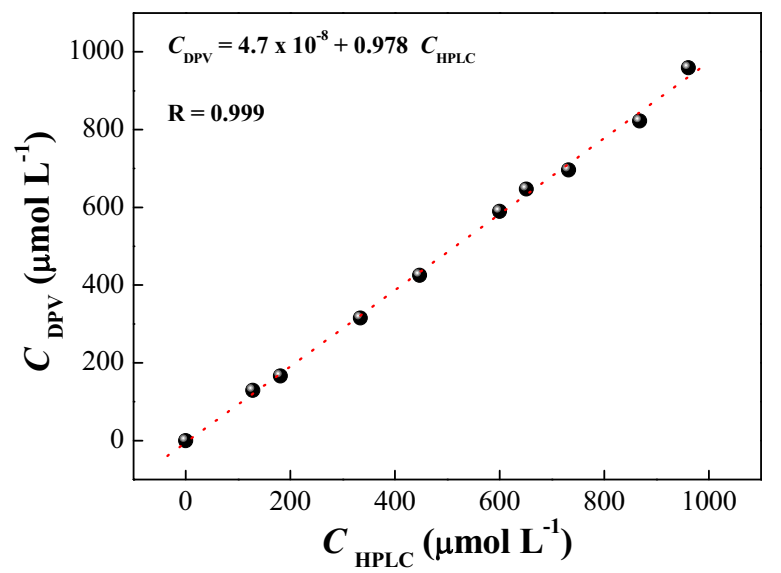

Fig. 4. Correlation between the results obtained by the proposed electroanalytical method and the standard (chromatography) method.

Table 1

Results for estriol quantification in real samples of creek water obtained by standard method (HPLC) and sensory platform (DPV).

\begin{tabular}{|c|c|c|c|c|c|c|}
\hline Added $\left(\mu \mathrm{mol} \mathrm{L}^{-1}\right)$ & HPLC detected $\left(\mu \mathrm{mol} \mathrm{L}^{-1}\right)$ & Recovered (\%) & Error (\%) & DPV detected $\left(\mu \mathrm{mol} \mathrm{L}^{-1}\right)$ & Recovered (\%) & Error (\%) \\
\hline 1.25 & 1.28 & 102.4 & 2.4 & 1.29 & 103.2 & 3.2 \\
\hline 1.75 & 1.81 & 103.4 & 3.4 & 1.66 & 94.8 & -5.6 \\
\hline 3.25 & 3.34 & 102.7 & 2.8 & 3.18 & 97.8 & -2.1 \\
\hline 4.25 & 4.47 & 105.1 & 5.2 & 4.30 & 101.1 & 1.1 \\
\hline 5.75 & 6.00 & 104.3 & 4.3 & 5.9 & 102.6 & 2.6 \\
\hline 6.25 & 6.51 & 104.1 & 4.2 & 6.37 & 101.9 & 1.9 \\
\hline 7.25 & 7.32 & 100.9 & 1 & 7.06 & 97.3 & -2.6 \\
\hline 8.25 & 8.68 & 105.2 & 5.2 & 8.34 & 101.1 & 1.1 \\
\hline 9.25 & 9.61 & 103.9 & 3.9 & 9.46 & 102.2 & 2.2 \\
\hline
\end{tabular}


Table 2

Performance of six transducers for electroanalytical sensing of estriol.

\begin{tabular}{|c|c|c|c|c|c|}
\hline Sensing layer & Transduction & Sensitivity $\left(\mu \mathrm{A} / \operatorname{mol~L}^{-1}\right)$ & $\operatorname{LOD}\left(\mu \mathrm{mol} \mathrm{L} \mathrm{L}^{-1}\right)$ & Linear range $\left(\mu \mathrm{mol} \mathrm{L} L^{-1}\right)$ & Reference \\
\hline MWCNT/SPCE & Amperometry & 0.001 & 0.53 & $1.0-1000.0$ & [19] \\
\hline SbNPs-rGO GC & DPV & 0.002 & 0.5 & $0.2-1.4$ & [7] \\
\hline MWCNTs/Pt/GC & SWV & 0.790 & 0.62 & $1.0-75.0$ & {$[18]$} \\
\hline BDDE & SWV & 0.002 & 0.17 & $0.2-20.0$ & {$[20]$} \\
\hline $\mathrm{Lac} / \mathrm{rGO} / \mathrm{Sb}_{2} \mathrm{O}_{5} / \mathrm{GC}$ & Amperometry & 0.275 & 0.01 & $0.025-1.03$ & [6] \\
\hline CNB-AgNP/GC & DPV & 0.131 & 0.16 & $0.2-3.0$ & This work \\
\hline
\end{tabular}

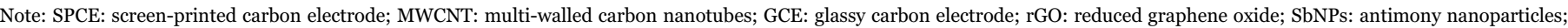
Pt: platinum; BDDE: boron doped diamond electrode; Lac: laccase; AgNP: silver nanoparticles; DPV: differential pulse voltammetry; SWV: square wave voltammetry.

curves with similar slopes between curve 1 and 2, confirming the robustness of the method. Moreover, the slopes were also similar between PBS solution and creek sample in the matrix effect study, as shown in Fig. S4B, i.e. there is no matrix effect.

Fig. 4 shows the correlation between the results from the sensor proposed and the standard method (HPLC) with an intercept value being close to zero and the slope and product-moment correlation coefficient close to one, i.e. the two techniques provide equivalent results. The random errors lead to a deviation from the optimal conditions [24,27]. In the Student's t-test the value of 63.4 (higher than the $\mathrm{t}$-critical value of 2.57 for $95 \%$ of significance and $n=10$ (degrees of freedom $=8 ; \alpha=0.05)$ ) showed insignificant difference between DPV and HPLC techniques [24,27]. Thus, the electroanalytical sensing performance yielded similar results as the standard HPLC methodology for estriol in creek surface water samples, with the improvement that there is no need of the sample pretreatment stage.

Table 2 summarizes the analytical efficiency of carbon-based sensing layers in terms of sensitivity $\left(\mathrm{A} \mathrm{L} \mathrm{mol}^{-1}\right)$, detection limits $\left(\mathrm{mol} \mathrm{L}{ }^{-1}\right.$ ) and linear range for estriol detection. The CNB-AgNP/GCE sensor exhibits the highest sensitivity and lowest detection limits. Furthermore, the limit of detection can be competitive with other devices for estriol detection, in a comparison with most modified materials $[6,7,18-20]$.

\section{Conclusion}

We have shown that carbon black decorated with silver nanoparticles (CNB-AgNP) with 5-6 nm diameter can be deposited on glassy carbon (GC) electrodes and promote oxidation of estriol at lower potentials than bare GCE, also yielding higher currents. The CNBAgNP/GCE sensor was then tested for detecting estriol, and showed the best performance in terms of sensitivity and detection limit $(0.131 \mu \mathrm{A} /$ mol $\mathrm{L}^{-1}$ and $0.16 \mu \mathrm{mol} \mathrm{L}{ }^{-1}$ ) among carbon-based electrochemical sensors we could find in the literature $\left(0.17-0.65 \mu \mathrm{mol} \mathrm{L}^{-1}\right)$. In addition, the electroanalytical performance of CNB-AgNP was sufficient to determine estriol concentration in natural waters of a creek. The CNB-AgNP/GCE sensor was also reproducible, stable and robust with regard to important interferents for estriol detection in biological samples. The excellent performance of CNB-AgNP for electrodes is particularly important for developing miniaturized analytical tools with low cost and simple fabrication procedures.

\section{Acknowledgments}

This work was supported by FAPESP (2012/17689-9, 2013/142627, 2014/05197-0, 2015/19099-2, 2016/01919-6, and 2016/12759-0), CNPq and CAPES (Brazil). Cabot Corporation and Prof. Marcos R. V. Lanza are acknowledged for the generous donation of carbon black VXC72R CNB. The authors are also grateful to Marcio de Paula and CAQI/IQSC/USP for the use of SEM facilities. The authors thank the Structural Characterization Laboratory/Department of Materials Engineering of the Federal University of São Carlos (LCE/DEMa/ UFSCar) for technical support during TEM analyses, respectively.

\section{Appendix A. Supplementary material}

Supplementary data associated with this article can be found in the online version at doi:10.1016/j.talanta.2017.06.058.

\section{References}

[1] T.C. Canevari, P.A. Raymundo-Pereira, R. Landers, E.V. Benvenutti, S.A.S. Machado, Sol-gel thin-film based mesoporous silica and carbon nanotubes for the determination of dopamine, uric acid and paracetamol in urine, Talanta 116 (2013) 726-735.

[2] T.C. Canevari, P.A. Raymundo-Pereira, R. Landers, S.A.S. Machado, Direct synthesis of Ag nanoparticles incorporated on a mesoporous hybrid material as a sensitive sensor for the simultaneous determination of dihydroxybenzenes isomers, Eur. J. Inorg. Chem. 2013 (33) (2013) 5746-5754.

[3] F.C. Vicentini, P.A. Raymundo-Pereira, B.C. Janegitz, S.A.S. Machado, O. FatibelloFilho, Nanostructured carbon black for simultaneous sensing in biological fluids, Sens. Actuators B: Chem. 227 (2016) 610-618.

[4] S. Mohsenian, M.S. Esmaili, J. Fathi, B. Shokri, Hydrogen and carbon black nanospheres production via thermal plasma pyrolysis of polymers, Int. J. Hydrog. Energy 41 (38) (2016) 16656-16663.

[5] S. Chandra Kishore, S. Anandhakumar, M. Sasidharan, Direct synthesis of solid and hollow carbon nanospheres over $\mathrm{NaCl}$ crystals using acetylene by chemical vapour deposition, Appl. Surf. Sci. 400 (2017) 90-96.

[6] F.H. Cincotto, T.C. Canevari, S.A.S. Machado, A. Sanchez, M.A.R. Barrio, R. Villalonga, J.M. Pingarron, Reduced graphene oxide- $\mathrm{Sb}_{2} \mathrm{O}_{5}$ hybrid nanomaterial for the design of a laccase-based amperometric biosensor for estriol, Electrochim. Acta 174 (2015) 332-339.

[7] I. Cesarino, F.H. Cincotto, S.A.S. Machado, A synergistic combination of reduced graphene oxide and antimony nanoparticles for estriol hormone detection, Sens. Actuators B: Chem. 210 (2015) 453-459.

[8] X. Luo, G. Li, Y. Hu, In-tube solid-phase microextraction based on NH2-MIL53(Al)-polymer monolithic column for online coupling with high-performance liquid chromatography for directly sensitive analysis of estrogens in human urine, Talanta 165 (2017) 377-383.

[9] V. Pacakova, L. Loukotkova, Z. Bosakova, K. Stulik, Analysis for estrogens as environmental pollutants - A review, J. Sep. Sci. 32 (5-6) (2009) 867-882.

[10] A.P. Fonseca, D.L.D. Lima, V.I. Esteves, Degradation by solar radiation of estrogenic hormones monitored by UV-Visible spectroscopy and capillary electrophoresis, Water Air Soil Poll. 215 (1-4) (2011) 441-447.

[11] L. Wang, F. Yuan, H.Q. Chen, B. Ling, J. Xu, Chemiluminescence of CdTe nanocrystals catalyzed by sodium hexametaphosphate and its sensitive application for determination of estrogens, Spectrochim. Acta A 91 (2012) 295-300.

[12] Z.L. Li, S. Wang, N.A. Lee, R.D. Allan, I.R. Kennedy, Development of a solid-phase extraction - enzyme-linked immunosorbent assay method for the determination of estrone in water, Anal. Chim. Acta 503 (2) (2004) 171-177.

[13] Y.P. Tang, S.Q. Zhao, Y.S. Wu, J.W. Zhou, M. Li, A direct competitive inhibition time-resolved fluoroimmunoassay for the detection of unconjugated estriol in serum of pregnant women, Anal. Methods 5 (16) (2013) 4068-4073.

[14] S. Nakamura, T.H. Sian, S. Daishima, Determination of estrogens in river water by gas chromatography-negative-ion chemical-ionization mass spectrometry, J. Chromatogr. A 919 (2) (2001) 275-282.

[15] P. Su, X.X. Zhang, Y.C. Wang, W.B. Chang, Direct immunoassay of estriol in pregnancy serum by capillary electrophoresis with laser-induced fluorescence detector, Talanta 60 (5) (2003) 969-975.

[16] S. Flor, S. Lucangioli, M. Contin, V. Tripodi, Simultaneous determination of nine endogenous steroids in human urine by polymeric-mixed micelle capillary electrophoresis, Electrophoresis 31 (19) (2010) 3305-3313.

[17] I. Ojeda, J. Lopez-Montero, M. Moreno-Guzman, B.C. Janegitz, A. Gonzalez-Cortes, P. Yanez-Sedeno, J.M. Pingarron, Electrochemical immunosensor for rapid and sensitive determination of estradiol, Anal. Chim. Acta 743 (2012) 117-124.

[18] X.Q. Lin, Y.X. Li, A sensitive determination of estrogens with a Pt nano-clusters/ multi-walled carbon nanotubes modified glassy carbon electrode, Biosens. Bioelectron. 22 (2) (2006) 253-259.

[19] L.M. Ochiai, D. Agustini, L.C.S. Figueiredo-Filho, C.E. Banks, L.H. MarcolinoJunior, M.F. Bergamini, Electroanalytical thread-device for estriol determination using screen-printed carbon electrodes modified with carbon nanotubes, Sens. 
Actuators B: Chem. 241 (2017) 978-984.

[20] K.D. Santos, O.C. Braga, I.C. Vieira, A. Spinelli, Electroanalytical determination of estriol hormone using a boron-doped diamond electrode, Talanta 80 (5) (2010) 1999-2006.

[21] S.E. Skrabalak, B.J. Wiley, M. Kim, E.V. Formo, Y.N. Xia, On the polyol synthesis of silver nanostructures: glycolaldehyde as a reducing agent, Nano Lett. 8 (7) (2008) 2077-2081.

[22] P.A. Raymundo-Pereira, A.R.F. Lima, S.A.S. Machado, A nanostructured label-free platform based on an ultrathin film for ultrasensitive detection of a secosteroid hormone, RSC Adv. 6 (41) (2016) 34458-34467.

[23] P.A. Raymundo-Pereira, D.A. Ceccato, A.G.B. Junior, M.F.S. Teixeira, S.A.M. Lima, A.M. Pires, Study on the structural and electrocatalytic properties of Ba2+- and Eu3+-doped silica xerogels as sensory platforms, RSC Adv. 6 (106) (2016) 104529-104536.

[24] P.A. Raymundo-Pereira, A.M. Campos, T.M. Prado, L.N. Furini, N.V. Boas, M.L. Calegaro, S.A.S. Machado, Synergy between Printex nano-carbons and silver nanoparticles for sensitive estimation of antioxidant activity, Anal. Chim. Acta 926 (2016) 88-98.

[25] H.Z. Lu, S.F.Xu, Mesoporous structured estrone imprinted $\mathrm{Fe}_{3} \mathrm{O}_{4} @ \mathrm{SiO}_{2} @ \mathrm{mSiO}_{2}$ for highly sensitive and selective detection of estrogens from water samples by HPLC, Talanta 144 (2015) 303-311.

[26] R.L. Perez, G.M. Escandar, Multivariate calibration-assisted high-performance liquid chromatography with dual UV and fluorimetric detection for the analysis of natural and synthetic sex hormones in environmental waters and sediments, Environ. Pollut. 209 (2016) 114-122.

[27] A.M. Campos, P.A. Raymundo-Pereira, C.D. Mendonça, M.L. Calegaro, S.A.S. Machado, O.N. Oliveira Jr., Printex 6L carbon Nanoballs used in electrochemical sensors for simultaneous detection of emerging pollutants hydroquinone and paracetamol, Sens. Actuators B: Chem. 252 (2017) 10.

[28] S. Nath, S.K. Ghosh, S. Praharaj, S. Panigrahi, S. Basu, T. Pal, Silver organosol: synthesis, characterisation and localised surface plasmon resonance study, New J. Chem. 29 (2005) 1527-1534.

[29] M.H.M.T. Assumpcao, R.F.B. De Souza, D.C. Rascio, J.C.M. Silva, M.L. Calegaro, I. Gaubeur, T.R.L.C. Paixao, P. Hammer, M.R.V. Lanza, M.C. Santos, A comparative study of the electrogeneration of hydrogen peroxide using Vulcan and Printex carbon supports, Carbon 49 (8) (2011) 2842-2851.

[30] A.C. Ferrari, J.C. Meyer, V. Scardaci, C. Casiraghi, M. Lazzeri, F. Mauri, S. Piscanec, D. Jiang, K.S. Novoselov, S. Roth, A.K. Geim, Raman spectrum of graphene and graphene layers, Phys. Rev. Lett. 97 (18) (2006) (187401-1-187401-187404).

[31] A.C. Ferrari, J. Robertson, Interpretation of Raman spectra of disordered and amorphous carbon, Phys. Rev. B 61 (20) (2000) 14095-14107.

[32] S. Cinti, F. Arduini, M. Carbone, L. Sansone, I. Cacciotti, D. Moscone, G. Palleschi, Screen-printed electrodes modified with carbon nanomaterials: a comparison among carbon black, carbon nanotubes and graphene, Electroanalysis 27 (9) (2015) 2230-2238.

[33] J.E.S. Fonsaca, A.L. Elias, S.H. Domingues, M.M. Oliveira, M. Endo, E.S. Orth, M. Terrones, A.J.G. Zarbin, Graphene nanoribbons inducing cube-shaped Ag nanoparticle assemblies, Carbon 93 (2015) 800-811.

[34] H. Mehl, M.M. Oliveira, A.J.G. Zarbin, Thin and transparent films of graphene/ silver nanoparticles obtained at liquid-liquid interfaces: preparation, characterization and application as SERS substrates, J. Colloid Interface Sci. 438 (2015) 29-38.

[35] A. Ambrosi, A. Bonanni, Z. Sofer, J.S. Cross, M. Pumera, Electrochemistry at chemically modified graphenes, Chem. Eur. J. 17 (38) (2011) 10763-10770.

[36] A.M. Campos, P.A. Raymundo-Pereira, F.H. Cincotto, T.C. Canevari, S.A.S. Machado, Sensitive determination of the endocrine disruptor bisphenol A at ultrathin film based on nanostructured hybrid material $\mathrm{SiO}_{2} / \mathrm{GO} / \mathrm{AgNP}$, J. Solid State Electrochem. 20 (9) (2016) 2503-2507.

[37] P.A. Raymundo-Pereira, M.F.S. Teixeira, F.R. Caetano, M.F. Bergamini, L.H. Marcolino, A simple and rapid estimation of totals polyphenols based on carbon paste electrode modified with ruthenium oxo-complex, Electroanalysis 27 (10) (2015) 2371-2376.

[38] J.P. Silveira, J.V. Piovesan, A. Spinelli, Carbon paste electrode modified with ferrimagnetic nanoparticles for voltammetric detection of the hormone estriol, Microchem. J. 133 (2017) 9.

[39] M.M. Ngundi, O.A. Sadik, T. Yamaguchi, S. Suye, First comparative reaction mechanisms of beta-estradiol and selected environmental hormones in a redox environment, Electrochem. Commun. 5 (1) (2003) 61-67. 